\title{
WHAT INFLUENCES BELIEVING CHILD SEXUAL ABUSE DISCLOSURES? THE ROLES OF DEPICTED MEMORY PERSISTENCE, PARTICIPANT GENDER, TRAUMA HISTORY, AND SEXISM
}

\author{
Lisa DeMarni Cromer and Jennifer J. Freyd \\ University of Oregon
}

\begin{abstract}
This vignette study investigated factors that influence believing child sexual abuse disclosures. College student participants $(N=318)$ in a university human subject pool completed measures about their own trauma history and responded to questions about sexist attitudes. Participants then read vignettes in which an adult disclosed a history of child sexual abuse, rated disclosures for accuracy and believability, and judged the level of abusiveness. Continuous memories were believed more than recovered memories. Men believed abuse reports less than did women, and people who had not experienced trauma were less likely to believe trauma reports. Gender and personal history interacted such that trauma history did not impact women's judgments but did impact men's judgments. Men with a trauma history responded similarly to women with or without a trauma history. High sexism predicted lower judgments of an event being abusive. Hostile sexism was negatively correlated with believing abuse disclosures. Results are considered in light of myths about child sexual abuse.
\end{abstract}

The rape myth literature burgeoned after Burt's (1980) influential article identified cultural myths and supports for rape and promoted an understanding of rape myth acceptance in our culture. Burt identified prejudicial, stereotyped, and false beliefs about rape (Burt, 1980). Lonsway and Fitzgerald (1994) further articulated rape myths as "generally false but... widely and persistently held, and

Lisa DeMarni Cromer and Jennifer J. Freyd, Department of Psychology, University of Oregon.

Lisa DeMarni Cromer is now at SUNY Upstate Medical University, Department of Psychiatry, in Syracuse, NY.

This research was supported in part by the Trauma and Oppression Research Fund at the University of Oregon Foundation and Center for the Study of Women in Society at the University of Oregon. We are grateful for the numerous contributions to this research made by Sanjay Srivastava and the members of the Freyd Dynamics Lab at the University of Oregon. Thanks to Anne DePrince, Kathryn Quina, and to our anonymous reviewers for helpful comments on earlier versions of this manuscript.

Preliminary results from this study were presented at the Annual Meeting of the American Association for the Advancement of Science, Seattle, WA, February 15, 2004.

Address correspondence and reprint requests to: Lisa DeMarni Cromer, SUNY Upstate Medical University, Department of Psychiatry, 713 Harrison St., Syracuse, NY 13210. E-mail: Cromerl@ upstate.edu that serve to deny and justify male sexual aggression against women" (p. 134). In reviewing the literature, Lonsway and Fitzgerald (1994) identified two overarching myths: (a) It is not uncommon for women to lie about having been raped and (b) Women are culpable when rape occurs, in that women who were raped have bad reputations or are from socially marginal or minority groups. The myth that women lie about rape enables the myth holder to deny that rape exists or at least deny that it is a prominent social problem. The myth that only certain women are raped, and that it happens only to people who are marginalized, is also protective for myth holders. Rape myths serve a protective function to enable one to feel either less vulnerable to trauma and/or less responsible for the social problem.

There is a parallel between the well-established rape myth literature and the small and emerging child sexual abuse myth (CSAM) literature. Similar to rape myths, which purport that women lie about rape, CSAMs include beliefs that women and children lie about child abuse and that incest is actually rare (Collings, 1997; Olafson, 2002). The persistence of this myth fueled sensationalized media cases such as the well-publicized 1990s McMartin case in California (see Manson, 1991, for discussion) and newspaper coverage about allegedly false accusations of abuse made in divorce and custody cases (Brown, Frederico, Hewitt, \& Sheehan, 2001). These myths are also propagated 
by child abuse backlash groups of accused perpetrators who claim they are innocent (Brown et al., 2001).

Another myth is that child sexual abuse is not actually abuse, nor is it harmful to the child (Collings, 1997). Evidence of the existence of this myth is seen in the lexical depiction of abuse, used by researchers and by the media, when descriptions contain consensual overtones such as "sexual intercourse" or "fondling" (Collings \& Bodill, 2003, p. 170). Tamarack (1986) noted similar myths that put positive spins on child sexual abuse and that state that children experience love, pleasure, and physical affection when they are the victims of incest. These myths are expounded by activist pedophile groups such as seen on The Pedophile Education Web site (http://lege.cz/win.en/archiv/pedo3.htm), which explicitly states in its "Pedo Credo" that "children are sexual and need release with [pedophiles]." Despite clear evidence that child sexual abuse is harmful (Freyd et al., 2005), some academic authors appear to support the myth of harmlessness (e.g., Rind, Tromovitch, \& Bauserman, 1998; for a critique see Dallam et al., 2001). Cheit and Freyd (2005) noted that the myths that child sexual abuse is rare and that child sexual abuse is not harmful are brandished by the same sources that promote a selfserving agenda.

The veracity of child sexual abuse reports is further challenged through a divorce myth about child sexual abuse (Brown et al., 2001). Just as doubt has been cast on rape reports when the media overpublicizes false rape accusations, child sexual abuse reports are questioned due to unfounded claims of child abuse in divorce cases being overpublicized. The myth may be partially driven by the same gender bias behind rape myths that purport that women make false allegations to "gain leverage" (Brown et al., 2001, p. 117). Research shows that less than $10 \%$ of child sexual abuse claims are likely to be false (Everson \& Boat, 1989), yet the media and fathers' rights groups make claims that up to $70 \%$ of child sexual abuse reports are false in divorce cases (Brown et al., 2001). Schudson (1992) noted that, although there is a lot of publicity about child sexual abuse allegations in divorce cases, only about $2 \%$ of child custody cases before courts actually involve child sexual abuse allegations and most of these are substantiated (p. 114). Thus, the fear induced by the media and by fathers' rights groups is oversensationalized in two respects. Underlying these fears is, as Brown and colleagues (2001) point out, a gender myth that women lie about abuse and rape for personal gain. Consequently, the accused male perpetrators take on the role of falsely accused victims.

When there is a perceived gain or motivation behind a child sexual abuse disclosure, the activated myths play upon one's sense of skepticism and fear (Brown et al., 2001; Schudson, 1992). It is likely that these myths and fears contribute to the doubts concerning adult delayed reports of child sexual abuse. Although adults are considered more reliable reporters compared to children, when there is a delay in the adult report of child sexual abuse, there is doubt as to the veracity of these claims, presumably because of suspicious motivations behind adults' reports. Although we know of no research that examines motivation for doubting adult disclosures, some have speculated that doubts are due to the possibility of memory decay over time (e.g., Golding, Sego, Sanchez, \& Hasemann, 1995). It will therefore be important to examine not only judgments of believability of the disclosure, but also the judged accuracy of memory when investigating factors that motivate the believability of delayed abuse disclosures.

Most of the previous research investigating beliefs about the veracity of abuse reports has been conducted in the psychology-and-law literature using mock jury studies. Because the legal system demands an edict of innocent until proven guilty, it is perhaps not surprising that victim reports are doubted and denials of alleged perpetrators are believed. Yet this literature tells us that stereotypes and myths about abuse and abuse reports influence judgments of believability (Read, 1997; Whitfield, Silberg, \& Fink, 2002). Interestingly, the most consistent factor that predicts trial outcome across studies is not a characteristic about the trial, but rather a characteristic of the juror: juror's gender. Men are far less likely to convict an accused perpetrator of child abuse than are women (Bottoms, Davis, \& Epstein, 2004; ForsterLee, Horowitz, Ho, ForsterLee, \& McGovern, 1999; Golding, Sego, \& Sanchez, 1999; Golding et al., 1995; Griffith, Libkuman, Kazen, \& Shafir, 1999; Griffith, Libkuman, \& Poole, 1998; Key, Warren, \& Ross, 1996; McCauley \& Parker, 2001; Quas, Bottoms, Haegerich, \& Nysse-Carris, 2003; Rotzien, 2003; Sugarman \& Boney-McCoy, 1997).

Little empirical work has examined factors that may moderate the impact of gender on believing disclosures. In discussing robust gender findings, in which female social workers believed abuse reports more than did male social workers, Jackson and Nuttall (1994) speculated that female social workers are more empathic than are male social workers because they are "nurturers and protectors of children (whether culturally or biologically determined)" (p. 110). Although they speculated that women may be more inclined to believe others' victimization reports because of their own gender's historical experiences of victimization, regression analyses indicated that personal histories of sexual abuse were less important for predicting believing scores than were young age and gender. Unfortunately, Jackson and Nuttall (1994) did not examine their data for an interaction effect between gender and trauma history, so we are unable to determine from this research if trauma history moderated the gender effects for believing.

Sexism has also been examined in relation to rape myth acceptance. Although sexism is often seen as a unitary construct, Glick and Fiske (1996) proposed a two-factor model of sexism, in which benevolent and hostile attitudes toward women exist. In describing ambivalent sexism, Glick and Fiske (1996) posited that benevolent sexism includes attitudes that are positive toward women if these women 
conform to traditional gender-role stereotypes. Conversely, hostile sexist attitudes are negative attitudes toward feminists and nonconforming women. Abrams, Viki, Masser, and Bohner (2003) examined ambivalent sexism in relation to rape myth acceptance and found that both forms of sexism were correlated with rape myth acceptance. The authors also found differences between the two types of sexism and victim culpability and rape proclivity. Respondents high in benevolent sexism found victims in acquaintance rape (but not stranger rape) to be culpable, presumably because these victims (all female) were not acting in the chaste manner expected within a benevolent sexist paradigm. Respondents high in hostile sexism were more prone to rape proclivity, which was consistent with predictions that hostile attitudes toward women would predict seeing aggressive sexual behavior toward women as socially acceptable. Furthermore, rape myth acceptance has been found to predict rape proclivity over and above the contribution of both types of sexism (Abrams et al., 2003). As far as we know, sexism has not been examined in relation to CSAM acceptance or examining judgments about child sexual abuse victims.

Researchers examining retrospective disclosures of child sexual abuse have assessed continuity of victim memory for its impact on believability of abuse reports. Read (1997) posited a trauma forgetting hypothesis (TFH) that purported a widespread social bias for believing that gaps in childhood memory provide evidence that child sexual abuse occurred. In a vignette study, Read (1997) found that college students presented with vignettes attributed memory discontinuity to child sexual abuse. Read speculated that self-help books and the media have created a bias in which discontinuity in memory is used to substantiate that abuse occurred. Although few would deny that amnesia may be an outcome of child sexual abuse, Read's TFH predicted that the publics' logic is the opposite- that amnesia would serve to prove that abuse had occurred. This question has been empirically examined by other researchers who have found evidence contrary to Read's hypothesis. Rather, there is reason to suggest that a bias exists against believing abuse reports. This evidence is reviewed below.

Studies have found that mock jurors have less confidence in delayed memories and are more likely to acquit the accused in delayed-memory cases regardless of evidence presented in the trial (Golding et al., 1999; Golding et al., 1995). This inclination in judgment is not limited to impartial observers or jurors; in clinical studies, actual victims doubt their own (corroborated) recovered memories. Dalenberg (1996) found that individuals with delayed autobiographical memory for actual child abuse had less confidence in their own delayed memories than in their own persistent memories, even when there was corroboration for the previously forgotten abuse. These studies point to the existence of a systematic bias for doubting delayed memories of child sexual abuse, irrespective of objective evidence.

The present research examines evidence for biases about child abuse reports based on CSAMs and memory heuris- tics. Several myths outlined above will be tested empirically in this study using vignettes of adults reporting childhood sexual and physical abuse to a college roommate. We have chosen not to utilize a mock jury vignette, as many previous studies have done, to remove judgment thresholds that result in guilty or not guilty verdicts. Inherent in jury decisions about the believability of a mock jury case are consequences for an alleged perpetrator, who is then deemed guilty or not guilty. To access social information and thoughts about victims, we asked participants to rate disclosure accuracy and believability rather than rate probable guilt or innocence of a perpetrator. Thoughts about disclosure accuracy and believability are critical from a public health perspective. It is well documented that child abuse is underreported and that most children do not disclose abuse when it is happening. For example, in a review of 11 studies, the modal rate of disclosure was only 33\% (London, Bruck, Ceci, \& Shuman, 2005). A substantial influence behind not disclosing is the fear of not being believed (Kellogg \& Huston, 1995) and fear of social rejection (Somer \& Szwarcberg, 2001). It is plausible that fears of not being believed may be well founded if there are social biases against believing child sexual abuse disclosures. If biases are found in the present study, it will indicate a need for education to encourage a social context in which victims can come forward.

The gender myth that women lie about abuse is tested by comparing disclosures by males and females. The myth that child sexual abuse is not really abusive or harmful is measured with a Likert-scale rating for each vignette. To test both Read's (1997) TFH and Golding and colleagues' (1999) suggestion that participants rely on memory heuristics, we varied memory persistence (either recovered or continuous) and asked participants to rate both accuracy (heuristic) and believability (TFH). Similar to Jackson and Nuttall (1994), we examined research participants' own abuse histories to search for a possible third variable that could moderate the gender effect of believing abuse reports. Moreover, extending the work of Abrams et al. (2003), which found that participant sexism impacted victim blaming and correlated with rape myth acceptance, we included the same sexism measure.

\section{Predictions}

Consistent with the child abuse myths described earlier, we predicted that female research participants would believe abuse disclosures and rate these disclosures as more accurate than would male participants. We examined whether gender of the victim has an effect on belief in disclosures because this is an area that has been relatively neglected in previous literature. We predicted that there would be a main effect for participants' sexual abuse histories, with individuals who have experienced abuse being more likely to believe reports of abuse than those without an abusive history. Sexism was expected to correlate with CSAMs, similar to earlier studies. Sexism was also used as an exploratory 
measure to determine whether sexism predicted level of believing abuse disclosures.

Using participants' ratings of abusiveness as a dependent variable, we sought to examine whether there was any evidence that college students hold the myth that child abuse is not harmful or abusive. Although we were interested in the relationship of sexism and trauma history to ratings of whether being made to have sex was considered abuse, we did not have specific between-group predictions. Prior research had found that sexism was related to believing that adult female victims were culpable and presumably had acted inappropriately so as to invite rape (Abrams et al., 2003). Thus, we expected a negative correlation between sexism and rating how abusive it was to the 9-year-old child who was made to have sex with an adult. Specifically, we expected that participants high in sexism would rate this as less abusive than participants low in sexism.

Our prediction about the continuity of memory runs opposite to Read's (1997) TFH, which suggested that disclosures that involve a recovered memory or delayed recall component would be believed more than memories that were continuous. We predicted the opposite effect, consistent with some authors' suggestions (e.g., Gaarder, 2000), that there is a propensity to disbelieve recovered memories because of the gender biases discussed earlier in this article. Specifically, recovered memories are believed to be doubted because they are part of a backlash against women and feminism (Gaarder, 2000). Thus, we predicted that males would be less likely to believe and rate as accurate recovered memories as compared to continuous memories.

\section{METHOD}

\section{Participants}

Undergraduate students (91 men, 227 women) in introductory psychology classes at the University of Oregon participated to partly fulfill a course requirement. Participants did not self-select into the study based on knowledge of the content; rather, participants were selected for the study based on schedule availability from a large human subject pool. Mean age was 19.75 years $(S D=3.49$, range $=17$ to 49). Participants were mostly Caucasian $(85.1 \%)$ and Asian $(9.8 \%)$.

\section{Design}

A $2 \times 2 \times 2$ (gender of participant $\times$ gender of victim $\times$ memory type) between-subject design was used for vignettes.

\section{Measures}

Each participant read two vignettes depicting sexual abuse. A sample vignette is:

A college friend, Susan, confides in you that she was forced by her father to have sex with him when she was
9 years old. Susan tells you that she has always remembered this aspect of her childhood, but she has never told anyone until now.

To vary victim gender, "Susan" was used to convey a female victim and "David" was used to convey a male victim. To vary memory "has always remembered" and "only recently remembered" were used. For grammatical purposes "but" in the continuous memory condition was changed to "and." The abuse in all vignettes occurred at age 9 and was described as not having been previously disclosed. Age 9 was chosen because it is well beyond the age of infantile amnesia, and it is within the age range in which child sexual abuse often occurs (Spiegel, 2003). In addition to the factors examined in this study, two other exploratory variables were manipulated: The two vignettes varied slightly by labeling of perpetrator (father vs. neighbor), and two additional vignettes depicted a specific form of physical abuse. Due to lack of stimulus control in wording choices, these exploratory manipulations were not examined in this study. We collapsed across perpetrator label in all analyses presented and did not include the items depicting physical abuse.

Participants made three ratings for each vignette. They rated believability on a scale ranging from 0 (not at all believable) to 5 (very believable), accuracy on a scale ranging from 0 (not at all accurate) to 5 (very accurate), and level of abuse on a scale ranging from 0 (definitely abuse) to 5 (not at all abuse). Each of these scores is used separately in the analyses.

The Ambivalent Sexism Inventory (ASI; Glick \& Fiske, 1996) is a 22-item self-report inventory of hostile and benevolent sexism. Participants indicated amount of agreement on a scale from 0 (disagree strongly) to 5 (agree strongly) with statements such as "Women seek to gain power by getting control over men" (hostile sexism) and "A good woman should be set on a pedestal by her man" (benevolent sexism). Previous studies have found the ASI to have good convergent, discriminant, and predictive validity, with alpha levels of .81 and .89, respectively (Glick \& Fiske, 1997). The alpha level for the current study was .87 .

Because we were interested in participants' own experiences of interpersonal trauma, we used the Brief Betrayal Trauma Survey (BBTS; Goldberg \& Freyd, 2006), which is a 12-item self-report inventory of low to high-betrayal trauma experiences. High betrayal trauma was used to operationalize interpersonal trauma. Examples of high-betrayal trauma were "You were made to have some form of sexual contact, such as touching or penetration, by someone with whom you were very close (such as a parent or lover)" and "You were emotionally or psychologically mistreated over a significant period of time by someone with whom you were very close (such as a parent or lover)." An example of a low-betrayal trauma is "Been in a major earthquake, fire, flood, hurricane, or tornado that resulted in significant loss of personal property, serious injury to yourself or a 
significant other, the death of a significant other, or the fear of your own death." Participants responded to the BBTS items on a 3-point scale of frequency of events over the lifetime: $0=$ never, $1=$ once or twice, $2=$ more than that. The BBTS has good test-retest reliability of $83 \%$ for childhood items and 75\% for events that occurred during adulthood (Goldberg \& Freyd, in press). Construct validity has been established between the BBTS and other measures of trauma (DePrince, 2001).

\section{Procedure}

Participants completed the measures as part of a General Survey in a psychology department human subject pool. This General Survey, completed by participants with schedule availability, contained a larger battery of about 20 short instruments from many researchers. Survey packets were completed in a large-group setting. Participants were given packets with a randomly assigned subject number and were informed both orally and in the written informed consent that their responses were anonymous. The battery of short measures was presented in 16 different randomized orders. The four between-subject versions of the vignettes were randomly placed in the 16 different measure packets and the vignettes presented to each subject were counterbalanced. The order of the ASI and BBTS was also randomized within the larger General Survey packet, and they were not directly adjacent to the vignettes or each other. After completing the surveys, participants deposited their packet in one of several boxes. Before leaving, they were given a paper credit slip to give to their instructor for course credit. No names of students were recorded by the experimenters so there was no way of identifying participants by their randomized subject number.

\section{RESULTS}

Accuracy and believability ratings were each examined using a between-subjects $2 \times 2 \times 2$ (victim sex $\times$ subject gender $\times$ memory type) multivariate analysis of variance (MANOVA). See Table 1 for means and standard deviations. Distributions for both types of ratings were normally distributed. Data were examined for outliers and none were identified. Assumptions of normality were satisfactorily met in the distributions. The MANOVA yielded a significant multivariate effect, Wilk's Lambda $=.92, F(2,309)=13.26$, $p<.001$.

\section{Gender of Participant}

As predicted, female participants believed disclosures more than did male participants, $F(1,310)=5.89, p<.05$, Cohen's $d=.30$, and rated abuse memories as more accurate than did males, $F(1,310)=4.81, p<.05$, Cohen's $d=.29$.

\section{Gender of Depicted Victim}

Contrary to prediction, disclosures by men were not believed more or rated as more accurate than disclosures by

\section{Table 1}

Mean $(S D)$ Believability and Accuracy Ratings for Male and Female Respondents in Different Vignette

Conditions

\begin{tabular}{lccc}
\hline & \multicolumn{2}{c}{ Respondents } & Total \\
\cline { 2 - 3 } & Female & Male & sample \\
\hline Continuous memory & & & \\
$\quad$ Believability & $4.19(.74)$ & $3.87(.97)$ & $4.10(.82)$ \\
Accuracy & $4.15(.78)$ & $3.93(.90)$ & $4.09(.82)$ \\
$N$ & 113 & 43 & 156 \\
Recovered memory & & & \\
$\quad$ Believability & $3.74(.95)$ & $3.50(1.12)$ & $3.67(1.01)$ \\
Accuracy & $3.57(1.00)$ & $3.25(1.29)$ & $3.48(1.10)$ \\
$N$ & 114 & 48 & 162 \\
Female victim & & & \\
$\quad$ Believability & $3.92(.87)$ & $3.65(1.11)$ & $3.84(.96)$ \\
Accuracy & $3.80(.92)$ & $3.56(1.18)$ & $3.73(1.01)$ \\
$N$ & 107 & 49 & 156 \\
Male Victim & & & \\
Believability & $4.00(.87)$ & $3.70(1.02)$ & $3.92(.93)$ \\
Accuracy & $3.91(.97)$ & $3.58(1.16)$ & $3.82(1.03)$ \\
$N$ & 120 & 42 & 162 \\
\hline
\end{tabular}

women. There was no participant gender by victim gender interaction.

\section{Type of Depicted Memory}

The between-subjects main effect for type of memory was significant (see Figure 1). As predicted, continuous memory was judged to be more believable, $F(1,310)=12.04$, $p<$ .0001 , Cohen's $d=.47$, and more accurate $F(1,310)=26.36$, $p<.0001$, Cohen's $d=.66$, than recovered memory.

\section{Participant Trauma History}

As predicted, gender and experiences of high-betrayal trauma significantly interacted for global ratings of believability (see Figure 2). A MANOVA using a four-level predictor variable (males/no high betrayal trauma $[n=50]$, males/high betrayal trauma $[n=41]$, females/no high betrayal trauma $[n=123]$, females/high betrayal trauma $[n=$ 104]) showed significant differences between groups for believability ratings, $F(3,314)=3.57, p<.05$, and differences that approached significance for accuracy ratings, $F(3,314)=2.35, p=.07$. The overall MANOVA was also significant, Wilk's Lambda $=.97, F(3,314)=3.5, p<.05$. Tukey's post hoc tests revealed that men with no high betrayal trauma believed disclosures less than both groups of women ( $p=.01$ for both). Men with at least one high betrayal experience did not have pairwise comparison differences with either group of women. The believability ratings between the two groups of men were not significantly different. Findings were less robust for accuracy rating of the memories. Post hoc tests showed that men with no high betrayal trauma experience rated memories as less accurate than did women with at least one high betrayal trauma 


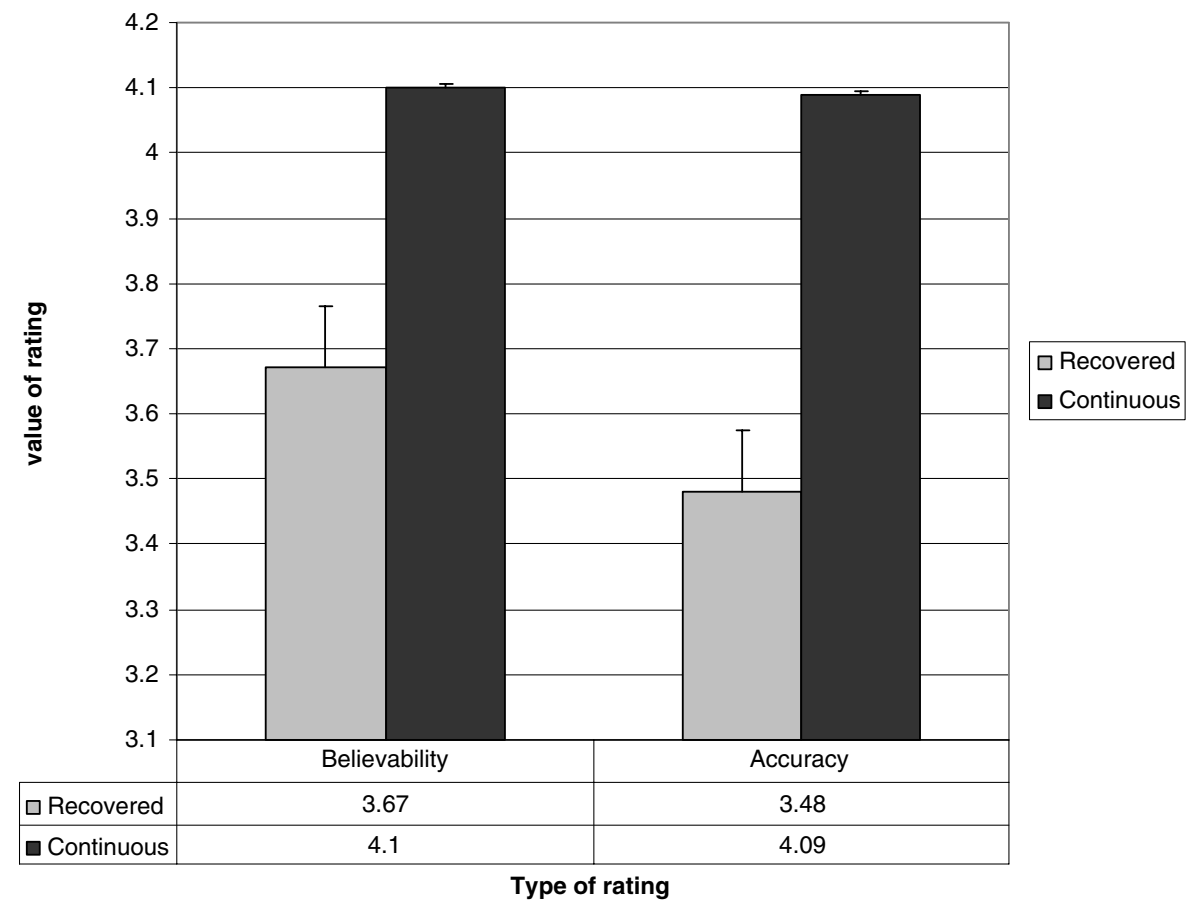

Fig. 1. Means with error bars showing believability and accuracy ratings of continuous versus recovered memories.

experience $(p=.05)$; other pairwise comparisons were not significant. A post hoc analysis of variance (ANOVA) was conducted to test the validity of this latter finding and to rule out that we had simply captured a response bias in which men with no high betrayal trauma history indiscriminately did not believe any of the vignettes of abuse. To examine this possible bias, rank order (i.e., high to low believable score) patterns of the vignettes between the four groups of participants were created. A test of linear trends (using the rank orders) enabled us to determine whether the men with no betrayal trauma distinguished between the four vignettes in the same manner as did the other participants.

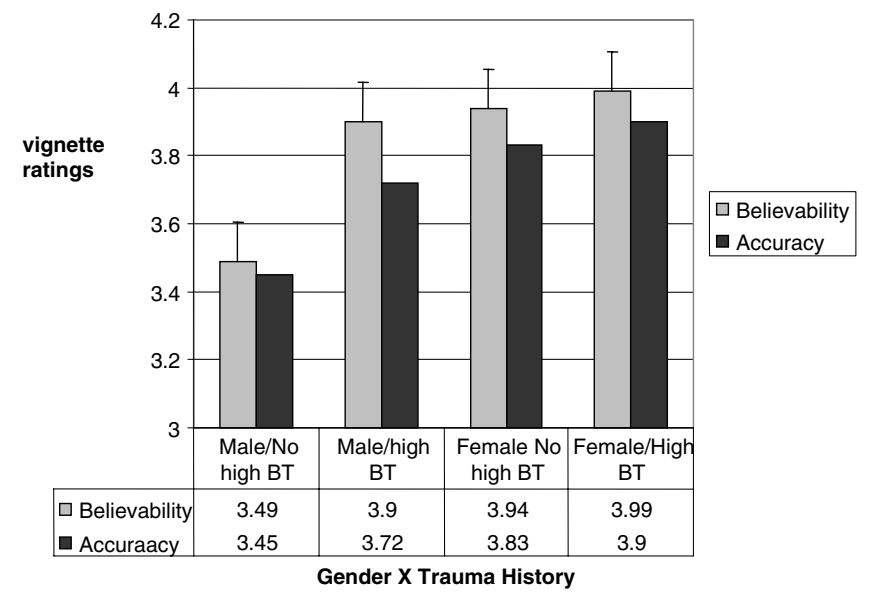

Fig. 2. Plotted means with error bars of believability and accuracy ratings for both genders with high and no high betrayal trauma history.
A second repeated measures ANOVA was conducted using gender and participant sexual abuse history as a dichotomous between-subject variable (men with no abuse vs. all other participants), and the four vignettes as one four-level within-subjects variable. The linear trend was significant, $F(1,227)=14.23, p<.001$. Thus, despite the disparity in group means, men who had not been abused ranked the vignettes in the same order for believability as had all the other subjects.

\section{Benevolent and Hostile Sexism}

Both benevolent and hostile sexism were significantly negatively correlated with ratings of whether the vignettes describing a child being made to have sex with an adult were considered abuse. Hostile but not benevolent sexism was negatively correlated with believing disclosures of child sexual abuse. Participants' own histories of high betrayal trauma were positively correlated with believing child sexual abuse disclosures but not with ratings of abusiveness. Correlations are provided in Table 2.

\section{DISCUSSION}

Consistent with decades of previous research, the present study found that women believed disclosures of child abuse more than did men. However, in examining other variables, such as trauma history, we found a more complex picture for understanding this gender difference. The prediction that participants' own trauma histories would interact with gender was supported. Men with no trauma history believed all abuse reports significantly less than did 
Table 2

Correlations of Study Measures $(N=243)$

\begin{tabular}{lcccc}
\hline & $\begin{array}{c}\text { Hostile } \\
\text { sexism }\end{array}$ & $\begin{array}{c}\text { High betrayal } \\
\text { trauma }\end{array}$ & Abuse? & Believing \\
\hline $\begin{array}{l}\text { Benevolent } \\
\text { sexism }\end{array}$ & $.534^{* *}$ & .08 & $-.20^{* *}$ & -.09 \\
$\begin{array}{l}\text { Hostile sexism } \\
\text { High betrayal }\end{array}$ & & .06 & $-.11^{*}$ & $-.11^{*}$ \\
$\quad$ trauma & & & .01 & $.13^{*}$ \\
Really abuse? & & & & .08 \\
\hline
\end{tabular}

${ }^{*} p<.05 .{ }^{* *} p<.001$.

males with a history of high betrayal trauma (e.g., sexual abuse by someone close) and women with and without high betrayal trauma histories. One possible explanation could be that one who has not had an abusive/traumatic experience may be more likely to doubt others' reports of such an experience. However, the interaction is particularly interesting: betrayal trauma experiences moderated men's but not women's ratings. When discussing similar findings in a sample of social workers, Jackson and Nuttall (1994) reasoned that women have historically played a nurturing and protective role for children and thus they may naturally have more empathy. Although there may be some validity to this empathy hypothesis, the interaction with male high betrayal experiences suggests an alternate explanation related to a culture of fear. Ferraro (1996) found that awareness of a close other's victimization predicted fear of interpersonal crime. Although fear of crime is not necessarily related to gender (see Sutton \& Farrall, 2005), women have a stronger perception of vulnerability to sexual assault than do men (Ferraro, 1996; Yodanis, 2004). Women's perceptions of vulnerability, regardless of their trauma histories, may make them more likely to believe others' reports of sexual assault. In contrast, men may lose their feelings of invulnerability when they have had an interpersonal trauma. In future research, it will be helpful to not only assess participants' trauma histories, but also to ask about their feelings of fear and vulnerability to possible assaults.

An alternative hypothesis for the gender/trauma history interaction may relate to disclosure behaviors. Women may be more likely to be the recipients of abuse disclosures given their role in society as nurturers. Thus, the female participants in our study may have had the personal experience of hearing someone's disclosure. This personal experience could also increase their likelihood of believing the disclosures in the vignettes, regardless of their own experiences with sexual assault or abuse. This knowledge of others' disclosures will be an important variable to examine in future research.

In addition to the gender differences in participants' responses, we had predicted that there would be differences based on victim gender, with male victims being believed more than female victims. One rape myth is that women lie about rape and thus we expected that women would be believed less when they reported child sexual abuse. The finding that there are no differences for male and female adults disclosing child abuse may be understood in that the parallel myth about child abuse is not gender specific. This myth purports that women and children lie about child abuse (Collings, 1997; Olafson, 2002). To better understand this gender dynamic, we will need to conduct studies that cross age of sexual assault (child vs. adult) with gender.

The most robust finding in this study supported the prediction that participants would believe continuous memory more than delayed memories and would see the former as more accurate. This finding suggests that there is a conflation of memory persistence and memory accuracy in conventional naïve theories of memory (Strevens, 2000) such as is seen in the recovered (persistence) versus false (accuracy) memory debate. This is an empirical question: Are unavailable memories, when recalled, more likely to be true or mistaken than continuously available memories? Although scholars have made both claims (that recovered memories are likely to be true and that recovered memories are more likely to be mistaken), research does not clearly support either position (Dalenberg, 1997; Freyd, 1998; Sivers, Schooler, \& Freyd, 2002; Williams \& Banyard, 1999). The present findings shed light on why child sexual abuse victims, when they recover their memories and have corroboration for these memories of abuse, still have selfdoubt (Dalenberg, 1997). It may not be qualitative aspects of the memories that cause doubts, but rather an inherent naïve bias about memories that, if they are true, then they are always present.

This naïve bias about memory may have implications for female victims. Women are more likely than men to be abused by someone close to them (Freyd \& Goldberg, 2004; Goldberg \& Freyd, 2006), and forgetting is more likely when the perpetrator is close to the victim (Freyd, 1996; Freyd, DePrince, \& Zurbriggen, 2001; Schultz, Passmore, \& Yoder, 2003). Hence, to the extent that women allege discontinuous memory for abuse experiences and to the extent such memory is doubted, women may be less likely to be believed.

Most previous research that examined bias about believing abuse reports has used methodology similar to the present study, but with the added circumstance of a mock trial with participants taking the role of juror. It is understandable that, with an edict of innocent until proven guilty, as the foundation for decision making, mock jurors would default to "not guilty" when there is empirical ambiguity. That delayed memories are less likely to be believed in the present study, in which believing the report was without consequence for an alleged perpetrator, suggests the presence of a general bias about believing delayed reports of abuse disclosures. The finding suggests that people believe 
that abuse must be salient and memorable if it really occurred.

The data indicated that, in cases of delayed recall compared to continuous recall, there is less likelihood that a friend would believe child sexual abuse disclosure. These findings are contrary to Read's (1997) TFH, which proposed that the public has an automatic bias toward assuming abuse occurred when there is a gap in memory for the abuse account. We evidenced the opposite: When there was a gap in memory, there was a bias against believing that abuse occurred.

From a public health perspective, believing or not believing disclosure is of clinical importance. It is well established in the literature that stigmatization and fear of rejection are deterrents to disclosing child sexual abuse (Somer \& Szwarcberg, 2001). The negative impact of child sexual abuse on health is clearly documented (e.g., Molnar, Buka, \& Kessler, 2001) as are the benefits of disclosure when that disclosure is perceived by the victim to be supportive (Hyman, Gold, \& Cott, 2003). However, nonsupportive disclosure can have a moderating effect that increases posttraumatic stress disorder symptoms (Hyman et al., 2003). Disclosing can be helpful; however, it can also be harmful to the victim. Thus, the existence of a bias against believing abuse is of critical health importance.

In addition to the findings that gender and trauma history interacted for believability ratings of child abuse, sexism was also found to correlate with perceptions of the abuse. The more sexist the participant (on measures of both hostile and benevolent sexism), the less likely they were to rate that a 9 -year-old being made to have sex with an adult was abuse. Although we do not know of any studies that have examined sexism and attitudes toward child abuse, this finding is consistent with studies that have found more sexist participants to both condone sexual coercion against women (Forbes, Adams-Curtis, \& White, 2004; Viki, Abrams, \& Masser, 2004) and to have a proclivity toward committing rape (Abrams et al., 2003). It has been suggested that sexist attitudes relate to the social acceptability of sexual aggressiveness toward women (Abrams et al., 2003). Indeed, in our data, respondents who were not sexist all viewed vignettes as abuse, whereas respondents high in sexism ranged in their scores with many scoring in the mid to high end of the scale (several responded with "not at all abuse"). Related to this, we also found that hostile sexism negatively correlated with believing child sexual abuse disclosures. Hostile attitudes toward women seem consistent with being suspicious about the veracity of abuse claims. Given the current findings, it seems that sexist attitudes relate to the social acceptability of aggression, or sexual entitlement, of men, regardless of victim gender and that hostile sexist attitudes relate to suspiciousness about abuse claims. Further, the relationship between sexist attitudes and reduced ratings of abusiveness suggests that sexist beliefs may diminish the perceived harm to victims of sexual crimes.

\section{Limitations and Future Directions}

One limitation of the present study is the sampling population of college students. College students are younger, from a higher socioeconomic class, and are more educated than community samples. Thus, the findings in this study should be generalized with caution. However, it is important to note that a strength of this study is that participants did not self-select into the study based on knowledge of the content; rather, participants were selected for the study based on schedule availability from a large human subject pool. Also, although vignette studies are often used in the social psychological literature, they nevertheless are somewhat artificial and as such may not accurately reflect how participants would respond to real abuse disclosures. Although the present study provides preliminary useful information, future studies should attempt to create more realism, perhaps through video vignettes or using live confederates in the lab to generate more ecologically valid responses. Additionally, based on the questions we asked, it is difficult to determine if participants specifically had a bias against believing that abuse occurred or if they had a bias against believing that people can recall that the abuse occurred. In the latter case, it may be possible to infer that the large main effects for memory suggest that participants do not have this bias against continuous memory. Future studies could ask more specific questions about beliefs about memories in general to better understand the mechanisms. Finally, Lonsway and Fitzgerald (1994) suggested that Lerner's (1980) just-world theory may be an etiological basis for rape myths being upheld. It is conceivable that beliefs in a just world could mediate beliefs in CSAMs. It would also be interesting to examine how beliefs in a just world may mediate gender effects and how they might be mediated by participants' trauma history. We are pursuing these questions in ongoing research.

\section{Summary and Implications}

We discovered evidence that the gender and personal trauma history of participants impacts willingness to believe abuse disclosure depicted in a vignette. In addition, the nature of the depicted memory influenced believability. Sexism influenced judgments of abusiveness and believability. These findings contribute to our understanding of biases in believing abuse disclosure. Belief in disclosure has significant implications, given that disclosure has the potential for positive health benefits to victims (Hyman et al., 2003). This study sheds light on possible hindrances to disclosure that have not before been identified. It also suggests that education campaigns about child sexual abuse may need to focus on dispelling traditional sexist beliefs about women as well as work to dispel CSAMs to successfully reduce its occurrence.

Initial submission: June 10, 2005

Initial acceptance: July 24, 2006

Final acceptance: September 25, 2006 


\section{REFERENCES}

Abrams, D., Viki, G. T., Masser, B., \& Bohner, G. (2003). Perceptions of stranger and acquaintance rape: The role of benevolent and hostile sexism in victim blame and rape proclivity. Journal of Personality and Social Psychology, 84, 111-125.

Bottoms, B. L., Davis, S. L., \& Epstein, M. A. (2004). Effects of victim and defendant race on jurors' decisions in child sexual abuse cases. Journal of Applied Social Psychology, $34,1-33$.

Brown, T., Frederico, M., Hewitt, L., \& Sheehan, R. (2001). The child abuse and divorce myth. Child Abuse Review, 10, 113124.

Burt, M. R. (1980). Cultural myths and supports for rape. Journal of Personality and Social Psychology, 38, 217-230.

Cheit, R., \& Freyd, J. J. (2005). Let's have an honest fight against child sex abuse [guest commentary]. Brown University Child \& Adolescent Behavior Letter, 21(6), 8.

Collings, S. J. (1997). Development, reliability and validity of the child sexual abuse myth scale. Journal of Interpersonal Violence, 12, 665-674.

Collings, S. J., \& Bodill, B. M. (2003). Methodological issues in research on child sexual abuse attributions. South African Journal of Psychology, 33(3), 170-175.

Dalenberg, C. D. (1996). Accuracy, timing and circumstances of disclosure in therapy of recovered and continuous memories of abuse. The Journal of Psychiatry \& Law, Summer, 229-275.

Dalenberg, C. D. (1997). The prediction of accurate recollections of trauma. In J. D. Read \& D. S. Lindsey (Eds.), Recollections of trauma: Scientific evidence b clinical practice (pp. 449-453). New York: Plenum Press.

Dallam, S. J., Gleaves, D. H., Cepeda-Benito, A., Silberg, J., Kraemer, H. C., \& Spiegel, D. (2001). The effects of child sexual abuse: Comment on Rind, Tromovitch, and Bauserman (1998). Psychological Bulletin, 127, 715733.

DePrince, A. P. (2001). Trauma and posttraumatic responses: An examination offear and betrayal. Unpublished doctoral dissertation, University of Oregon, Eugene.

Everson, M. D., \& Boat, B. W. (1989). False allegations of sexual abuse by children and adolescents. Journal of the American Academy of Child and Adolescent Psychiatry, 28, 230235.

Ferraro, K. F. (1996). Women's fear of victimization: Shadow of sexual assault? Social Forces, 75, 667-690.

Forbes, G. B., Adams-Curtis, L. E., \& White, K. B. (2004). Firstand second-generation measures of sexism, rape myths and related beliefs, and hostility toward women: Their interrelationships and association with college students' experiences with dating aggression and sexual coercion. Violence Against Women, 10, 236-261.

ForsterLee, R., Horowitz, I. A., Ho, R., ForsterLee, L., \& McGovern, A. (1999). Community members' perceptions of evidence: The effects of gender in a recovered memory civil trial. Journal of Applied Psychology, 84, 484495.

Freyd, J. J. (1996). Betrayal trauma: The logic of forgetting childhood abuse. Cambridge, MA: Harvard University Press.

Freyd, J. J. (1998). Science in the memory debate. Ethics of Behavior, 8, 101-113.
Freyd, J. J., DePrince, A. P., \& Zurbriggen, E. L. (2001). Self-reported memory for abuse depends upon victimperpetrator relationship. Journal of Trauma \& Dissociation, $2(3), 5-17$.

Freyd, J. J., \& Goldberg, L. R. (2004). Gender difference in exposure to betrayal trauma. Presentation at the 20th Annual Meeting of the International Society for Traumatic Stress Studies, New Orleans, LA, November 14-18, 2004.

Freyd, J. J., Putnam, F. W., Lyon, T. D., Becker-Blease, K. A., Cheit, R. E., Siegel, N. B., \& Pezdek, K. (2005). The science of child sexual abuse. Science, 308, 501.

Gaarder, E. (2000). Gender politics: The focus of women in the memory debates. Journal of Child Sexual Abuse, 9(1), 91106.

Glick, P., \& Fiske, S. T. (1996). The ambivalent sexism inventory: Differentiating hostile and benevolent sexism. Journal of Personality \& Social Psychology, 70, 491-512.

Glick, P., \& Fiske, S. T. (1997). Hostile and benevolent sexism: Measuring ambivalent sexist attitudes toward women. Psychology of Women Quarterly, 21, 119-135.

Goldberg, L. R., \& Freyd, J. J. (2006). Self-reports of potentially disturbing experiences in an adult community sample: Gender differences in event frequencies, test-retest stabilities, and the hierarchical factor structure of the items in a brief betrayal-trauma survey. Journal of Trauma \& Dissociation, 7(3), 39-63.

Golding, J. M., Sego, S. A., \& Sanchez, R. P. (1999). The effect of multiple childhood sexual assaults on mock-jurors' perceptions of repressed memories. Behavioral Sciences and the Law, 17, 483-493.

Golding, J. M., Sego, S. A., Sanchez, R. P., \& Hasemann, D. (1995). The believability of repressed memories. Law and Human Behavior, 19, 569-592.

Griffith, J. D., Libkuman, T. M., Kazen, J., \& Shafir, Z. (1999). Repressed memories in the courtroom: Trial characteristics affecting mock jurors' decision making. American Journal of Forensic Psychology, 17(2), 5-24.

Griffith, J. D., Libkuman, T. M., \& Poole, D. A. (1998). Repressed memories: The effects of expert testimony on mock jurors' decision making. American Journal of Forensic Psychology, 16(1), 5-23.

Hyman, S. M., Gold, S. N., \& Cott, M. A. (2003). Forms of social support that moderate PTSD in childhood sexual abuse survivors. Journal of Family Violence, 18, 295-300.

Jackson, H., \& Nuttall, R. (1994). Effects of gender, age, and history of abuse on social workers' judgments of sexual abuse allegations. Social Work Research, 18, 105-113.

Kellogg, N. D., \& Huston, R. L. (1995). Unwanted sexual experiences in adolescents: Pattern of disclosure. Clinical Pediatrics, 34, 306-312.

Key, H. G., Warren, A. R., \& Ross, D. F. (1996). Perceptions of repressed memories: A reappraisal. Law and Human Behavior, 20, 555-563.

Lerner, M. J. (1980). The belief in a just world: A fundamental delusion. New York: Plenum Press.

London, K., Bruck, M., Ceci, S. J., \& Shuman, D. W. (2005). Disclosure of child sexual abuse:What does the research tell us about the ways that children tell? Psychology, Public Policy, and Law, 11, 194-226.

Lonsway, K. A., \& Fitzgerald, L. F. (1994). Rape myths: In review. Psychology of Women Quarterly, 18, 133-164. 
Manson, M. (1991). The McMartin case revisited: The conflict between social work and criminal justice. Social Work, 36, 391-395.

McCauley, M. R., \& Parker, J. F. (2001). When will a child be believed? The impact of the victim's age and juror's gender on children's credibility and verdict in a sexual-abuse case. Child Abuse \& Neglect, 25, 523-539.

Molnar, B. E., Buka, S. L., \& Kessler, R. C. (2001). Child sexual abuse and subsequent psychopathology: Results from the national comorbidity survey. American Journal of Public Health, 91, 753-760.

Olafson, E. (2002). When paradigms collide: Roland Summit and the rediscovery of child sexual abuse. In J. R. Conte (Ed.), Critical issues in child sexual abuse: Historical, legal, and psychological perspectives (pp. 139-173). Thousand Oaks, CA: Sage.

Quas, J. A., Bottoms, B. L., Haegerich, T. M., \& Nysse-Carris, K. L. (2003). Effects of victim, defendant and juror gender on decisions in child sexual assault cases. Journal of Applied Social Psychology, 32, 1993-2021.

Read, J. D. (1997). Memory issues in the diagnosis of unreported trauma. In J. D. Read \& D. S. Lindsay (Eds.), Recollections of trauma: Scientific evidence and clinical practice (pp. 79108). New York: Plenum Press.

Rind, B., Tromovitch, P., \& Bauserman, R. (1998). A meta-analytic examination of assumed properties of child sexual abuse using college samples. Psychological Bulletin, 124, 2253.

Rotzien, A. L. (2003). Factors influencing juror verdict in a case involving repressed memories of abuse. Current Psychology: Developmental, Learning, Personality, Social, 21, 220-239.

Schudson, C. B. (1992). Antagonistic parents in family courts: False allegations or false assumptions about true allegations of child sexual abuse? Journal of Child Sexual Abuse, 1, 113-116.

Schultz, T. M., Passmore, J., \& Yoder, C. Y. (2003). Emotional closeness with perpetrators and amnesia for child sexual abuse. Journal of Child Sexual Abuse, 12, 67-88.
Sivers, H., Schooler, J., \& Freyd, J. J. (2002). Recovered memories. In V. S. Ramachandran (Ed.), Encyclopedia of the human brain (Vol. 4, pp. 169-184). San Diego, CA; London: Academic Press.

Somer, E., \& Szwarcberg, S. (2001). Variables in delayed disclosure of childhood sexual abuse. American Journal of Orthopsychiatry, 71, 332-341.

Spiegel, J. (2003). Sexual abuse of males: The SAM model of theory and practice. New York: Brunner-Routledge.

Strevens, M. (2000). The essential aspect of naïve theories. Cognition, 74, 149-175.

Sugarman, D. B., \& Boney-McCoy, S. (1997). Impact of expert testimony on the believability of repressed memories. Violence and Victims, 12, 115-126.

Sutton, R. M., \& Farrall, S. (2005). Gender, socially desirable responding and the fear of crime: Are women really more anxious about crime? British Journal of Criminology, 45, 212-224.

Tamarack, L. I. (1986). Fifty myths and facts about child sexual abuse. In E. Schlesinger (Ed.), Sexual abuse of children in the 1980s (pp. 3-15). Toronto, Canada: University of Toronto Press.

Ullman, S. E. (2003). Social reactions to child sexual abuse disclosures: A critical review. Journal of Child Sexual Abuse, 12, 89-121.

Viki, G. T., Abrams, D., \& Masser, B. (2004). Evaluating stranger and acquaintance rape: The role of benevolent sexism in perpetrator blame and recommended sentence length. Law and Human Behavior, 28, 295-303.

Whitfield, C. L., Silberg, J., \& Fink, P. J. (2002). Misinformation concerning child sexual abuse and adult survivors. Binghamton, NY: Hawthorn.

Williams, L. M., \& Banyard, V. L. (1999). Trauma \& memory. Thousand Oaks, CA: Sage.

Yodanis, C. L. (2004). Gender inequality, violence against women, and fear: A cross-national test of the feminist theory of violence against women. Journal of Interpersonal Violence, $19,655-675$. 